\title{
GLIAL REPAIR IN AN INSECT CENTRAL NERVOUS SYSTEM: EFFECTS OF SELECTIVE GLIAL DISRUPTION ${ }^{1}$
}

\author{
P. J. S. SMITH, ${ }^{2}$ C. A. LEECII, AND J. E. TREHERNE \\ Agricultural Food Reserve Council Unit of Insect Neurophysiology and Pharmacology, Department of Zoology, University of \\ Cambridge, CB2 $3 E J$ United Kingdom
}

Received December 27, 1983; Revised April 23, 1984; Accepted May 8, 1984

\begin{abstract}
In vivo application of ethidium bromide to cockroach central nervous connectives caused extensive disruption of the neuroglia within $24 \mathrm{hr}$. Axonal conduction persisted following treatment with the glial toxin. A consistent feature of glial damage and repair was the prominent involvement of granule-containing cells. These cells (which were never seen in control cords) shared a number of cytological features with hemocytes that were seen adhering to and penetrating the neural lamella, in the early stages of glial damage.

The granule-containing cells appear to serve dual functions: phagocytosis and structural repair. After $48 \mathrm{hr}$, granule-containing cells, or their processes, formed layers at the periphery of the connectives. By 4 to 6 days after treatment, the peripheral cells had assumed the morphological characteristics of normal perineurial cells and by 28 days were indistinguishable, ultrastructurally, from those of the perineurium of normal, untreated animals. These structural changes paralleled the re-establishment of the normal permeability properties of the blood-brain interface revealed by the exclusion of an extracellular tracer, ionic lanthanum, and electrophysiological obscrvations.
\end{abstract}

One of the major difficulties in the study of the mechanisms of neural repair is the complexity of cellular responses induced by mechanical damage. These responses involve a variety of cell types, and it is often impossible to recognize their relative contributions and interactions in the subsequent restoration of neuronal function (e.g., Gilmore and Walls, 1981). Such difficulties are encountered even in the relatively simple nervous system of an insect in which, as described in the preceding paper (Treherne et al., 1984), surgical lesioning induces complex changes in neuronal, glial, and extracellular elements.

In the present investigation we have studied glial repair in cockroach central nervous connectives following selective disruption of the neuroglia, using ethidium bromide as a glial toxin. This compound, which binds to both DNA and RNA (Waring, 1981), was applied in vivo to nervous connectives which contain only glial nuclei, thus leaving the axons intact. Ethidium bromide has been used previously to induce demyelination in mammalian spinal cord (Blakemore, 1982) and subpial axons (Yajima and Suzuki, 1979a, b). Treatment with a glial toxin produces a simplified situation for there is no disruption of the neurons, which maintain excitability throughout, nor is there appreciable mechanical damage to the extracellular elements, the neural lamella, or the underlying intercellular matrix.

\section{Materials and Methods}

Adult male cockroaches (Periplaneta americana (L.)) from the laboratory culture were used in all experiments. Animals were anesthetized

${ }^{1}$ This research was supported in part by a grant from the United States European Research Office. We thank Drs. N. J. Lane and W. F. Blakemore for their advice and criticism and Mr. B. Harrison for assistance during the ultrastructural work.

${ }^{2}$ To whom correspondence should be addressed. by immersion under water for $4 \mathrm{~min}$ and then were restrained, ventral surface uppermost, on a Sylgard plate. Dissection tools were dipped in alcohol and flamed before and during the operation. A flap of cuticle was lifted to allow access to the connective between the 4th and 5 th ganglia of the abdominal nerve cord.

Application of the gliotoxin. The gliotoxin, ethidium bromide (Blakemore, 1982), was applied to the nerve cord as follows. Tissue covering the connective was carefully moved to one side and a small stainless steel platform, smeared with grease (Apiezon N), was used to lift the connective from the abdominal cavity. A grease well was formed over the cord on the platform and filled with a $25 \mathrm{~mm}$ solution of ethidium bromide in cockroach saline. Cockroach saline had the following composition: $157 \mathrm{mM} \mathrm{NaCl}, 3 \mathrm{mM} \mathrm{KOH}, 2 \mathrm{mM} \mathrm{CaCl}, 2 \mathrm{mM} \mathrm{MgCl}$; $5 \mathrm{mM}$ trehalose; $8.6 \mathrm{~mm}$ HEPES buffer ( $\mathrm{pH} 7.4$ ). The osmolarity and $\mathrm{pH}$ of the saline were not appreciably altered by the addition of ethidium bromide.

The section of the cord in the well (about 1 to $2 \mathrm{~mm}$ in length) was approximately in the center of the connectivc. During the 10-min period of application, ethidium diffused down the cord. Approximately 2 to 3 $\mathrm{mm}$ of the cord was colored by ethidium bromide after $10 \mathrm{~min}$. In control experiments cords were treated with saline alone. At the end of the treatment, ethidium bromide was removed and the connective was thoroughly washed with saline, before being repositioned in the abdominal cavity. Any tissue which originally covered the cord was replaced and the cuticle was closed and sealed using low melting point wax.

Fixation and embedding. Animals were killed by decapitation. They were dissected from the dorsal surface and flooded with fixative. The treated area of the connective was cut out and placed in fresh fixative (2.5\% glutaraldehyde in 0.05 m Sorensen's phosphate buffer $(\mathrm{pH} 7.2)$ with $6 \%$ sucrose added). The tissue was fixed for 1 to $2 \mathrm{hr}$ at room tcmperature and then overnight at $4^{\circ} \mathrm{C}$, after which it was washed in buffer plus sucrose, postfixed in $1 \%$ osmium tetroxide plus sucrose for 60 min at room temperature, washed, and then stained en bloc in $2 \%$ uranyl acelate. Dehydration through an ascending series of alcohols and propylene oxide led to embedding in Araldite. Ultrathin sections were cut transversely through the cord on either an LKB Ultrotome III or a Reichert-Jung Ultracut. A diamond knife was essential; the treated tissue was very prone to breaking up on cutting and badly 

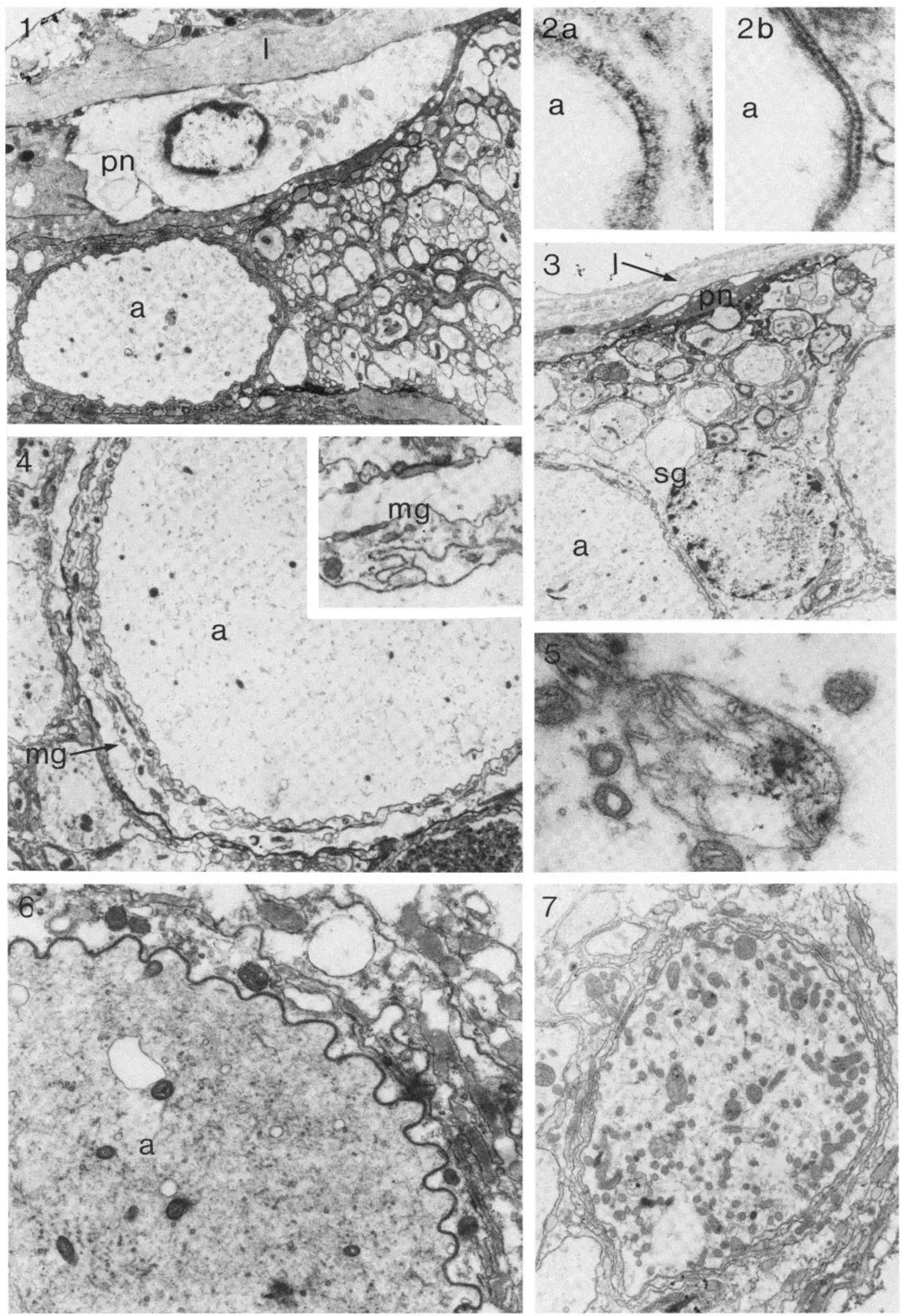


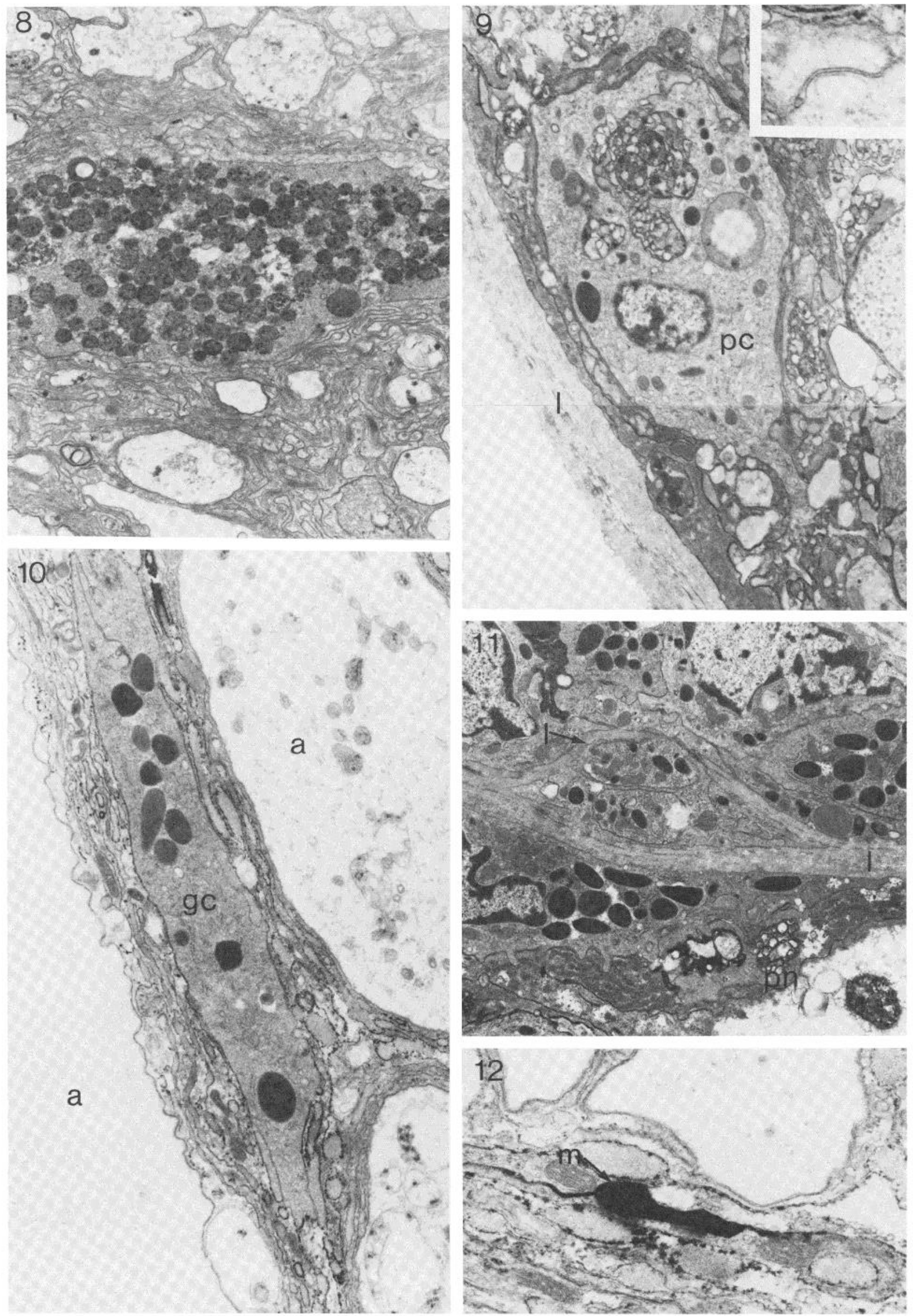




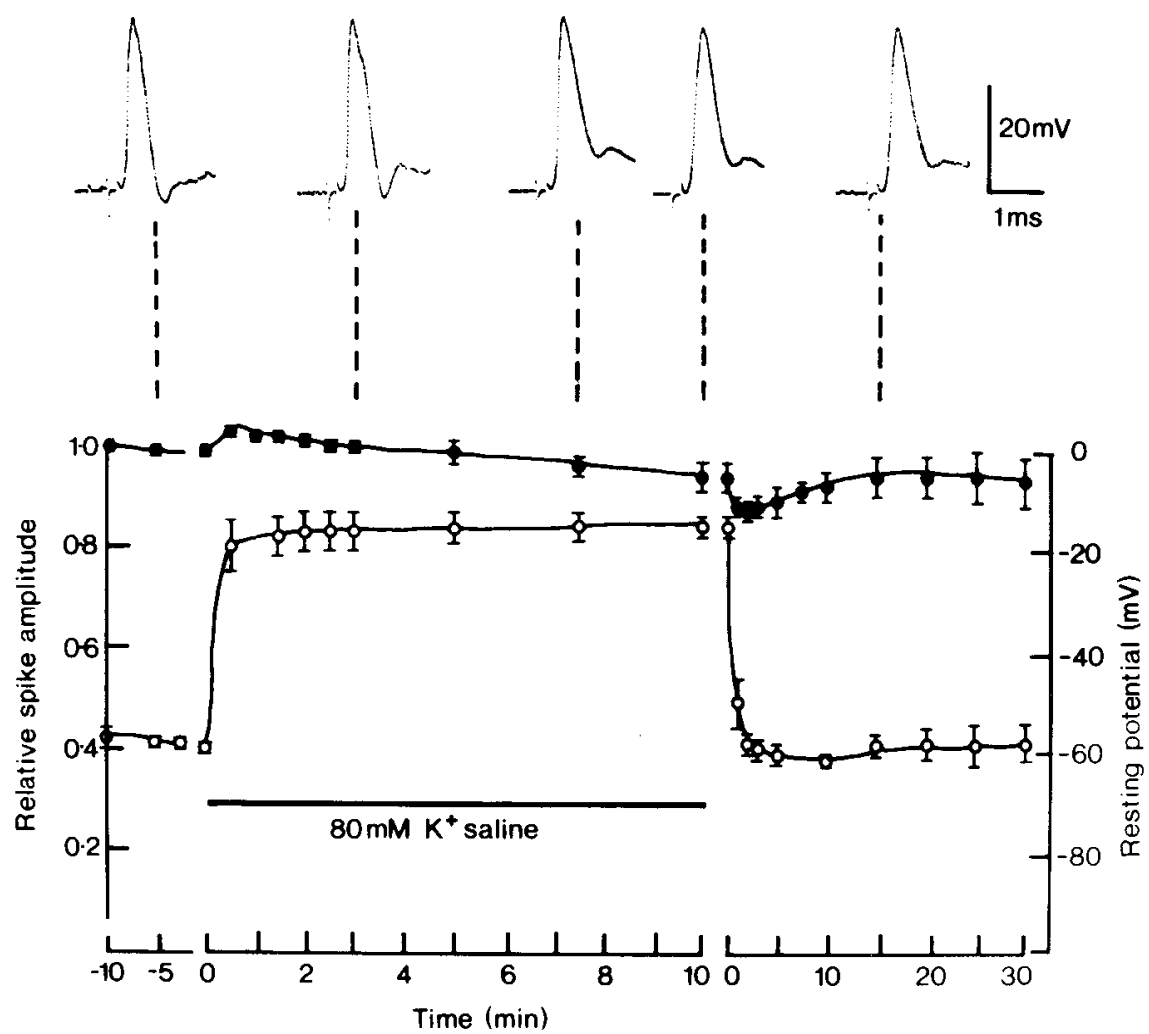

Figure 13. Relative spike amplitude from sucrose gap preparations $(; n=3)$ with the simultaneous records of the resting potential $(O)$ during the exposure of normal cockroach nerve cords to high-potassium saline. Despite the sharp rise in the DC potential the spike amplitude remains unaffected as $\mathrm{K}^{+}$access to the inwardly directed membranes is restricted by occluding junctional complexes in the intact perineurium. Standard errors are shown on both sides of the mean.

scored conventional glass knives. Sections were stained with lead citrate and uranyl acetate, and were examined in a Philips EM300 microscope.

Lanthanum incubation. Incubation in ionic lanthanum was done in vitro by immersing the entire abdominal connective in a solution of 10 $\mathrm{mM} \mathrm{LaCl} 3$ made up in the phosphate-free cockroach saline. After 30 min incubation the lanthanum was precipitated in the tissue, in situ, using the phosphate-buffered glutaraldehyde fixalive, and the areas for embedding were cut out. This tissue was then fixed, embedded, and cut as described above.

${ }^{3}$ The abbreviations used in the figures are: $a$, axon; $g$, granule; $g c$, granule-containing cell; $h c$, hemocyte; $l$, neural lamella; $m g$, mesoaxonal glia; $p c$, phagocytotic cell; $p n$, perineurium; $s g$, subperineurial cell.
Physiology. The electrophysiological properties of ethidium-treated nerve cords were investigated using intracellular and sucrose gap techniques. Nerve cords were isolated and mounted in an experimental chamber (Treherne et al., 1973) with the treated region in the central compartment. Salines were perfused continuously ( 3 to $4 \mathrm{ml} / \mathrm{min}$ ) and could be changed using a non-return valve (Holder and Sattelle, 1972). Nerve cords were stimulated electrically near the terminal ganglion. High $[\mathrm{K}]$ saline $(80 \mathrm{mM}[\mathrm{K}])$ was produced by substitution of $\mathrm{K}$ for the $\mathrm{Na}$ of normal cockroach saline. High $[\mathrm{K}]$ salines were used in physiological experiments to assess the integrity of the blood-brain barrier (Treherne and Pichon, 1972).

Intracellular records were obtained using $3 \mathrm{M} \mathrm{KCl-filled} \mathrm{microelec-}$ trodes connected to a WPI M701 microprobe; records were displayed on a Medelec fiber-optic oscilloscope and recorded on Kodak linagraph

Figure 1. ${ }^{3}$ Perineurial damage $24 \mathrm{hr}$ after treatment with ethidium bromide. The nuclear chromatin is clumped and cytoplasm is disrupted in a perineurial cell treated with lanthanum chloride. Magnification $\times 5,200$.

Figure 2. Junctional-like structure between glial and adjacent giant axon membranes $24 \mathrm{hr}$ post-treatment. Magnification: $a, \times 162,350 ; b, \times$ 84,800 .

Figure 3. Structural abnormalities in the subperineurial glia $48 \mathrm{hr}$ after treatment with ethidium bromide. Magnification $\times 3,390$.

Figure 4. Disruption of the mesoaxonal glia round a giant axon. Magnification $\times 6,210$. The inset is a higher power photograph of this area. Magnification $\times 20,320$. The axon appears normal $(48 \mathrm{hr}$ post-treatment).

Figure 5. Axonal mitochondria $24 \mathrm{hr}$ after ethidium bromide treatment. Some have an electron-dense granular appearance in both lanthanumtreated and untreated preparations. Magnification $\times 15,110$-treated with lanthanum chloride.

Figure 6. Infolding of the axonal membrane at 2.5 days after treatment with ethidium bromide. Magnification $\times 16,130$.

Figure 7. An axon with an abnormally large number of mitochondria, $48 \mathrm{hr}$ after ethidium bromide treatment. Magnification $\times 10,500$.

Figure 8. A large area of cellular debris in the nerve cord $48 \mathrm{hr}$ after ethidium bromide treatment. Magnification $\times 7,620$.

Figure 9. A phagocytotic granule-containing cell under the neural lamella. The inset is a higher power photograph showing the join where the cell is engulfing some cellular debris, presumably perineurium $48 \mathrm{hr}$ post-treatment. Magnification $\times 9,260$.

Figure 10. A granule-containing cell lying within the glial folds adjacent to a giant axon, $48 \mathrm{hr}$ post-treatment, incubated in lanthanum chloride. Magnification $\times 10,150$.

Figure 11. Granule-containing hemocytes lying on both sides of the neural lamella, $48 \mathrm{hr}$ post-treatment. Some of these cells are also within the neural lamella. Magnification $\times 5,210$.

Figure 12. Lanthanum phosphate in the subperineurial extracellular spaces $48 \mathrm{hr}$ after ethidium bromide treatment. Magnification $\times 29,100$. 


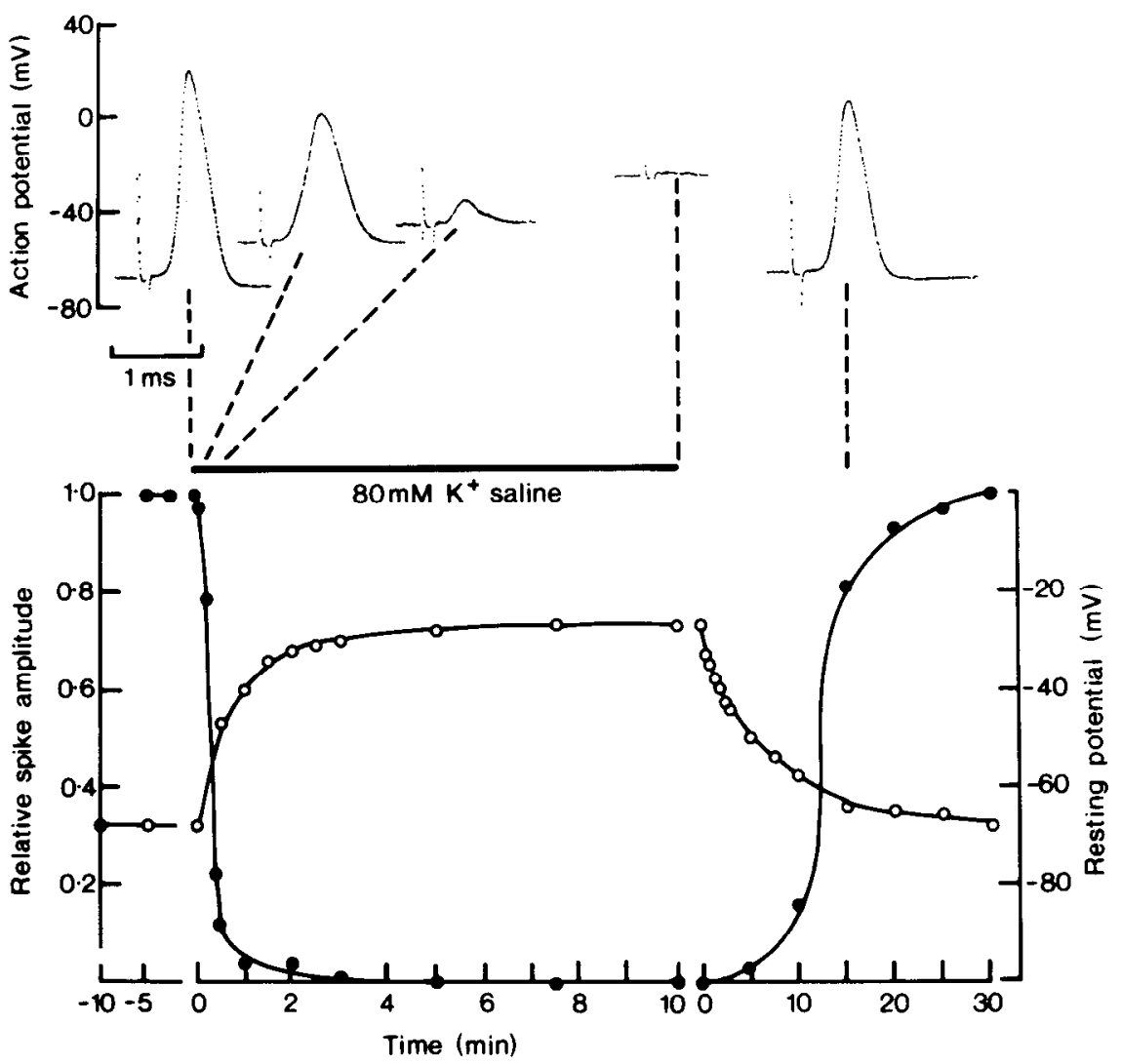

Figure 14. Relative spike amplitude (@) from the intracellular recordings shown above with the concomitant changes in the resting potential $(O), 1$ day after the application of ethidium bromide. The blood-brain barrier is now disrupted and the DC potential change results from changes in the axonal resting potential. This effect is reflected by the rapid loss of the action potential on exposure to the high-potassium saline.

paper. Resting potentials were monitored on a Linseis pen recorder. All experiments were performed at room temperature.

\section{Results}

\section{Effects $1-2$ days after treatment}

Ultrastructure. Morphological and physiological effects of exposure of connectives to ethidium bromide were detectable after $24 \mathrm{hr}$. There were marked changes in perineurial ultrastructure, including clumping of nuclear chromatin and extensive damage to the perineurial cytoplasm (Fig. 1). The underlying glial elements and the axons were not markedly affected at this stage, except for some disruption of the cytoplasm of the mesoaxonal glial processes and the appearance of junctional-like structures, between adjacent glial and giant axonal membranes, which were not seen in control cords (Fig. 2, $a$ and b).

Forty-eight hours after ethidium treatment extensive perineurial damage was accompanied by obvious ultrastructural abnormalities in the subperineurial glia (Fig. 3). Clear spaces were now apparent in the cytoplasm of mesaxonal glia, adjacent to the axon (Fig. 4). In general, the ultrastructural appearance of the axons was little modified by the treatment. In some areas, however, there were slight abnormalities in the appearance of the mitochondria (Fig. 5). Infrequently, more extensive changes were seen in the axoplasm, including infoldings of the axonal membranes (Fig. 6) and increased numbers of the mitochondria (Fig. 7). Occasionally, areas of cellular debris were seen (Fig. 8).

A consistent feature of the early ethidium effects was the appearance of cells containing electron-dense granules both within the disrupted perineurium and at deeper levels. No such cells were seen in untreated cords. In some ethidium-treated cords these granule-containing cells were clearly phagocytotic (Fig. 9). In others, particularly deeper within the cord, their shape was more fusiform (Fig. 10).

Cytoplasmic granules are a common feature of insect hemocytes, which were seen on both sides of the neural lamella after ethidium treatment (Fig. 11). The granules were indistinguishable from those seen in both phagocytic and fusiform cells. After $48 \mathrm{hr}$, when healthy nuclei were seen in cells (either in the vicinity of axons or in particular, within the perineurium), granules were frequently present within the cytoplasm.

Lanthanum penetration. In normal, untreated cords the perineurial glia constitute the blood-brain barrier which restricts the extracellular penetration of small, water-soluble cations (Treherne and Schofield, 1981; Schofield and Treherne, 1984) and also excludes electron-dense extracellular markers, including ionic lanthanum (Lane and Treherne, 1972; Lane, 1981). However, in 24- and 48-hr ethidium-treated cords, externally applied lanthanum penetrated into the subperineurial extracellular spaces (Figs. 10 and 12).

Electrophysiology. A breakdown of the superficial blood-brain barrier following ethidium treatment was also indicated by our electrophysiological observations (using intracellular microelectrode and sucrose gap techniques). In normal nerve cords, dissected directly from the animals, the integrity of the perineurial blood-brain barrier was shown by the persistence of action potentials and the large DC potential changes measured during external application of high-potassium saline (Fig. 13). The changes in DC potential have been postulated (Pichon and Treherne, 1970; Pichon et al., 1971) and indicated by recordings from identified perineurial glia (Schofield et al., 1984) to result from depolarization of the outwardly directed perineurial mem- 

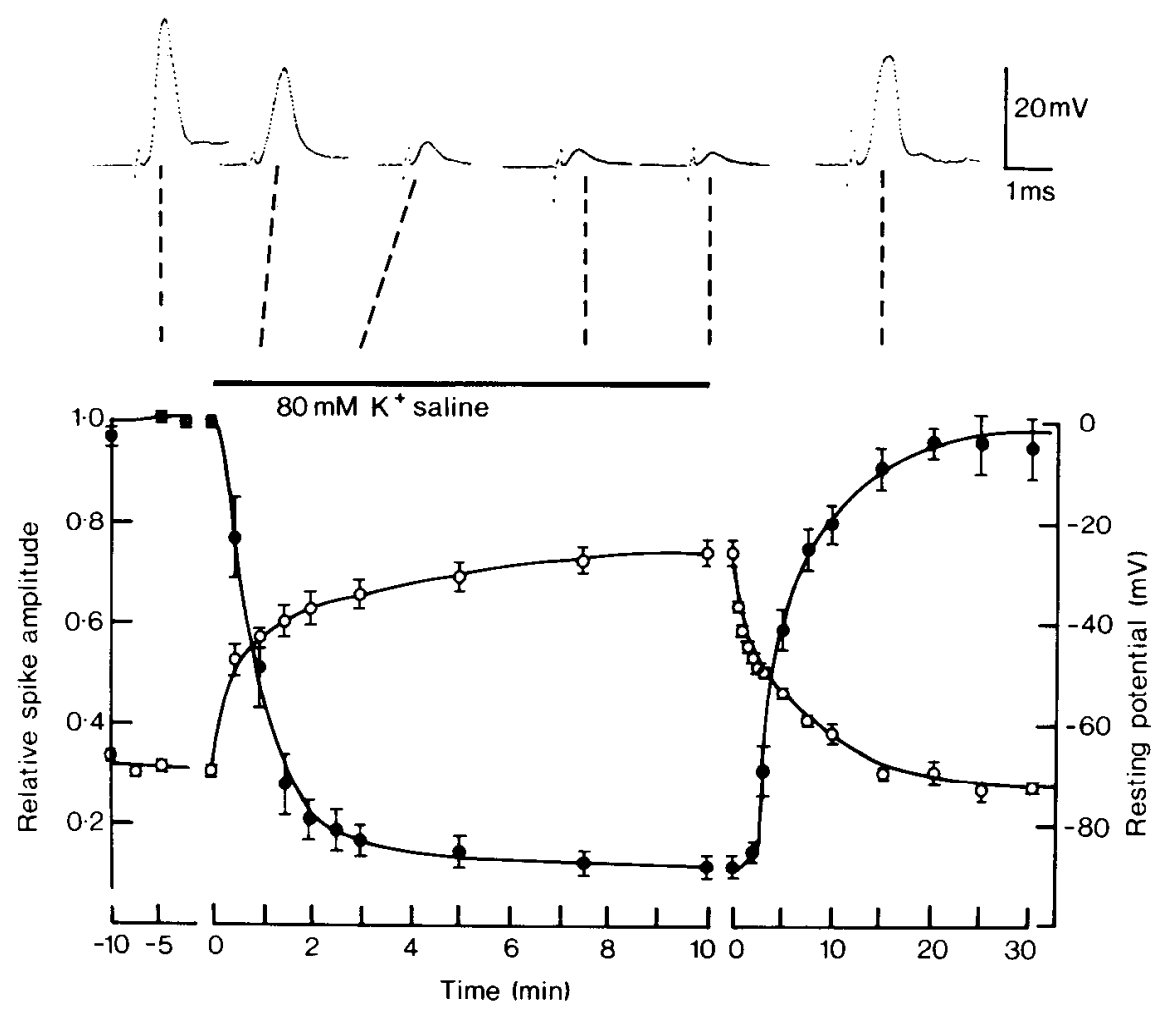

Figure 15. Two days after treatment with ethidium bromide the relative spike amplitude (-) and resting potentials $(O)$ from sucrose gap recordings $(n=5)$ reflect an access of potassium to the axon surface; these results are similar to the intracellular recording shown in Figure 14. Standard errors are shown on both sides of the mean.

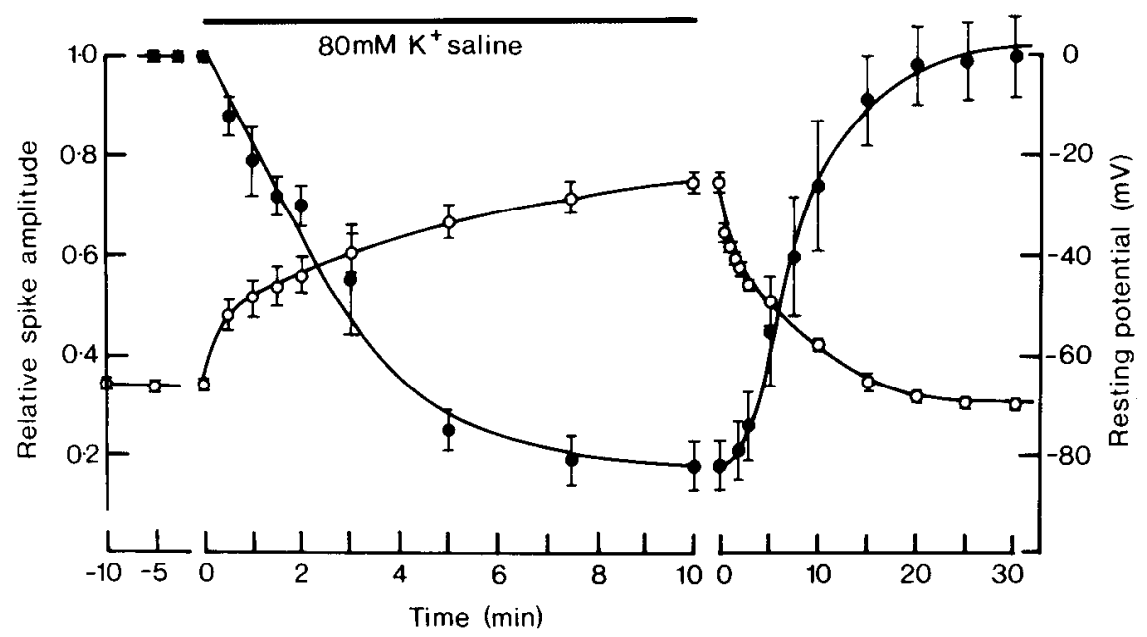

Figure 16. Although stretching a connective can also cause intercellular leakage, the rate at which the sucrose gap-recorded action potential $(\bullet)$ is reduced on exposure to high-potassium saline (cords treated 2 days before with only saline) is slower than for those exposed to the ethidium bromide $(n=5)$. Standard errors are shown on both sides of the mean.

branes, access to the inwardly directed ones being restricted by occluding junctional complexes in the perineurial clefts.

Such results contrast with those observed in experimental nerve cords $24 \mathrm{hr}$ after ethidium treatment. In these preparations there was a rapid decline in action potential amplitude on exposure to high-potassium saline (Fig. 14), indicating a rapid access of the cations to the axon surfaces. Under these circumstances the depolarization and subsequent repolarization (recorded intracellularly and with the sucrose gap) had slower time courses and, according to previous interpretations (Pichon et al., 1971), result largely from changes in axonal resting potential. Essentially similar results were obtained up to $48 \mathrm{hr}$ (Fig. 15).

It is known that the electrical responses of cockroach central nervous connectives can be modified by handling during experimental preparation, an increased intercellular leakage of water-soluble cations being induced by modest stretching of the connectives (Pichon and Treherne, 1970). This effect was observed in control experiments in which exposed connectives were treated only with saline (Fig. 16). Such control cords also showed some ultrastructural modifications, notably separation of the perineurial cells and occasional changes in the appear- 


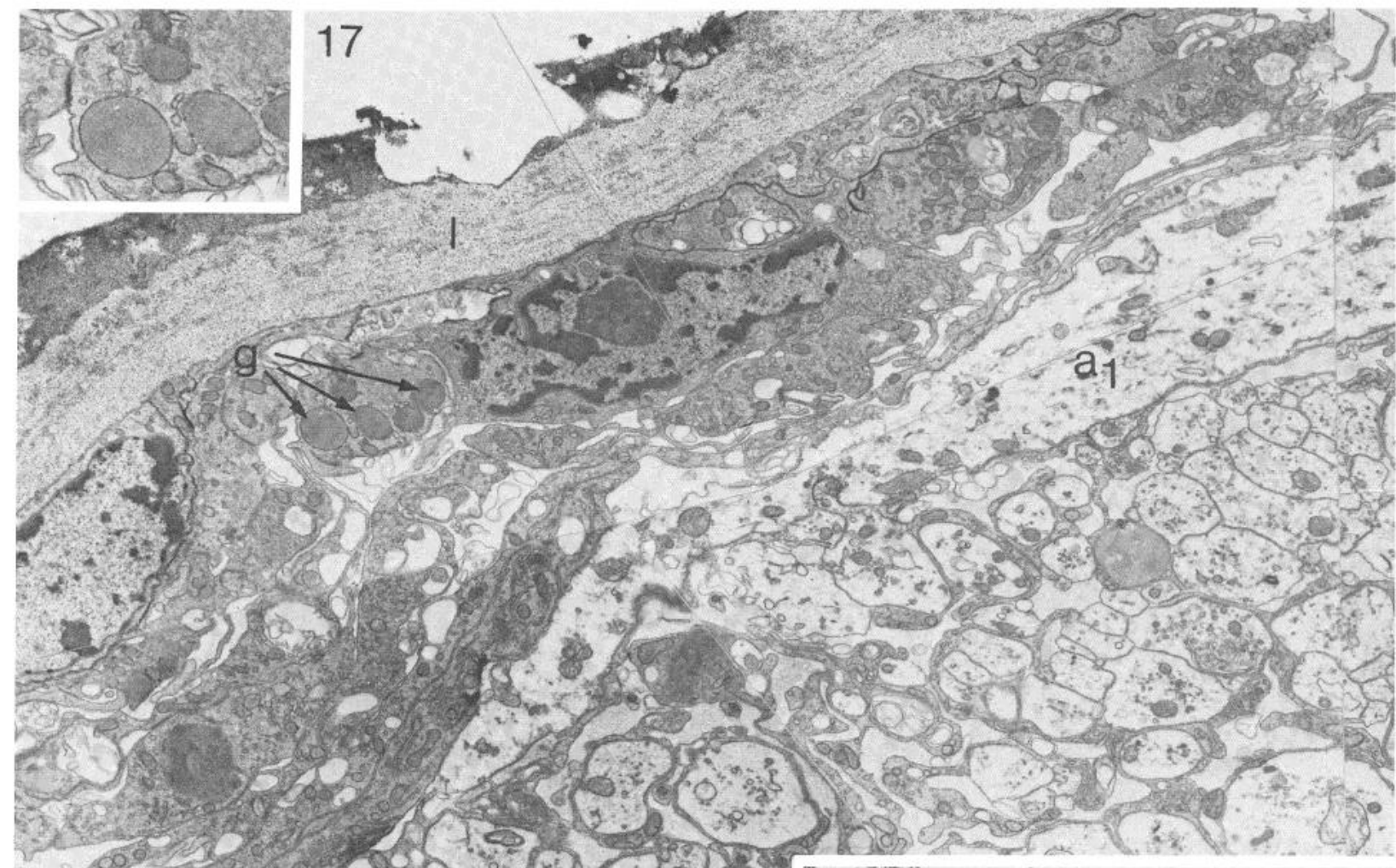

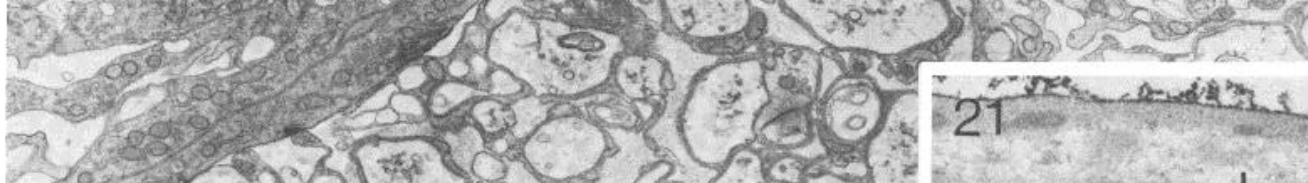

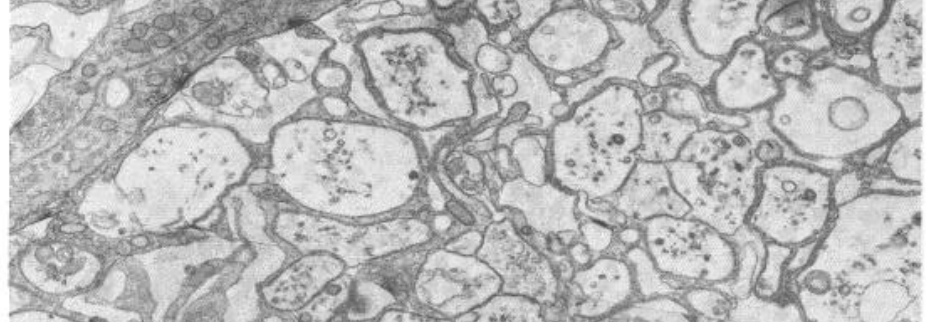
ai
3.

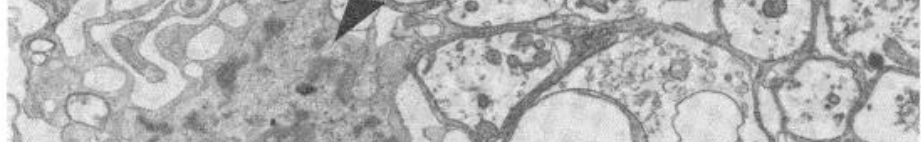

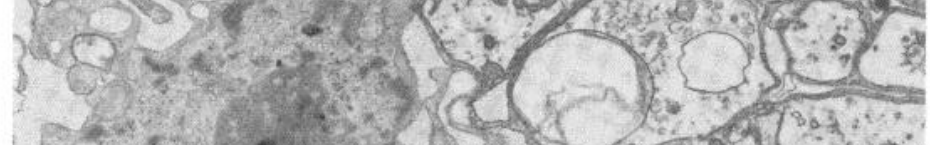

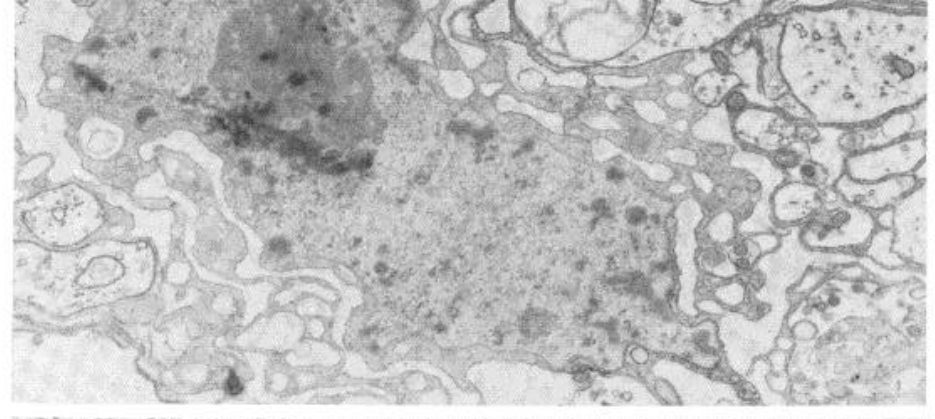
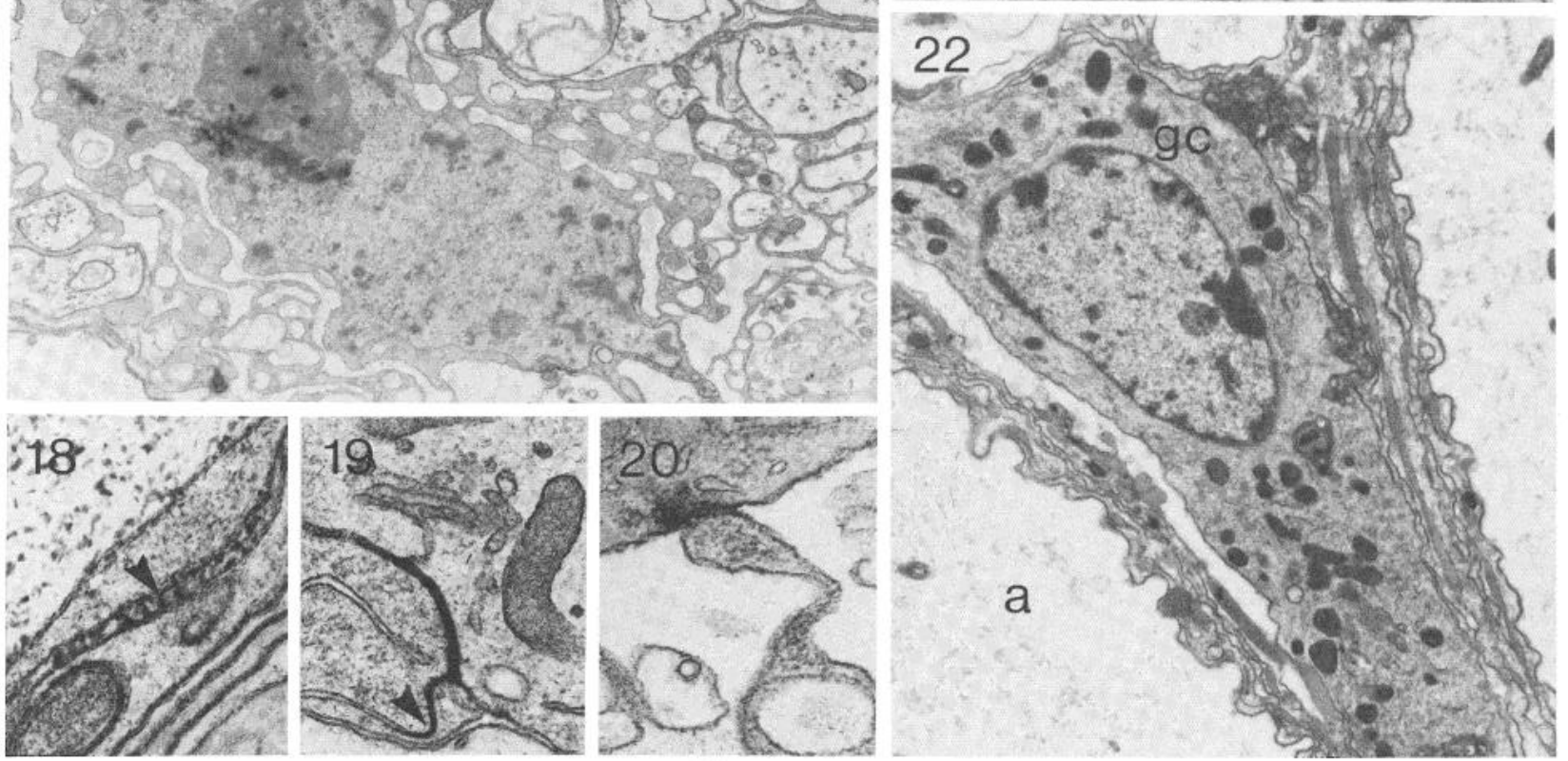

Figures 17 to 22 

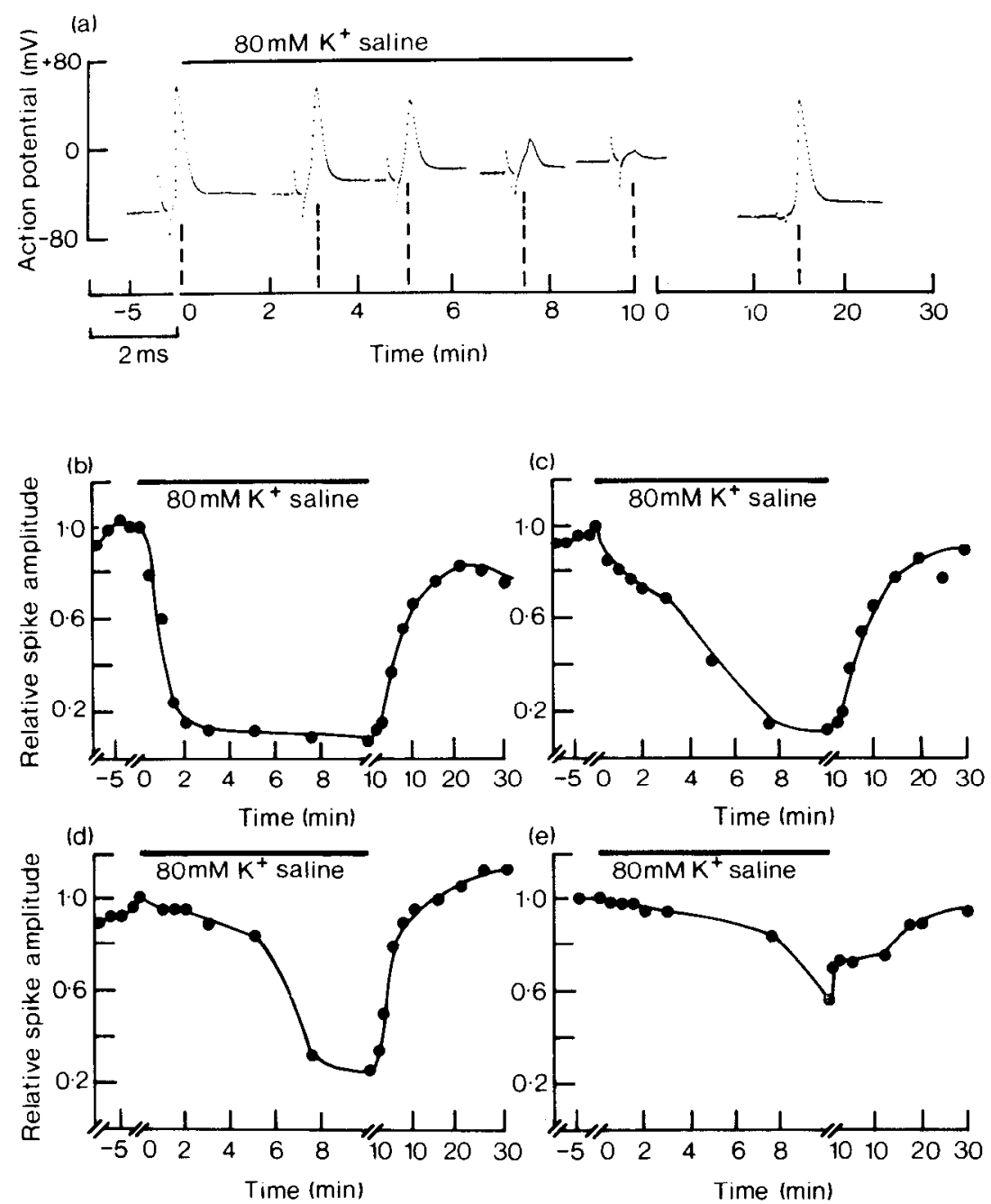

Figure 23. Relative spike amplitude ( $b$ to $e$, sucrose gap recordings) with an intracellular record $(a)$ from preparations 4 days after treatment with ethidium bromide. At this stage there is more variation in the response to the high-potassium saline.

ance of the cytoplasm, but in all cases the nuclei appeared normal. The unavoidable increase in intercellular leakage caused by the experimental procedure probably facilitated the penetration of ethidium bromide to the subperineurial tissues. Our observations indicate that ethidium treatment, nevertheless, further increases the rate of access of potassium ions to the axon surfaces, for the decline in spike amplitude occurred more rapidly than in the saline-treated controls (Fig. 15).

\section{Effects at 4 days after treatment}

Ultrastructure. At this stage undamaged cells were observed at the periphery of the connectives, underlying the neural lamella: their nuclei appeared normal, and the cytoplasm contained considerable amounts of Golgi apparatus and smooth endoplasmic reticulum together with large electron-opaque granules (Fig. 17). These cytoplasmic features were very differ- ent from those observed in normal perineurial cells. As shown in Figure 17, these cells possess extensive, interdigitating cell processes with atypical, large extracellular spaces. Apparent junctional complexes, possibly septate and tight, were present between the membranes of adjacent cell processes (Figs. 18 and 19). Other preparations at this time showed a closer layering of these superficial cells and reduced extracellular spaces (Fig. 21) - a feature also seen at later stages of repair and typical of normal perineurium. Granule-containing cells were present both within the superficial layer and at deeper levels within the connectives (Fig. 22). Also present were atypical cells (Fig. 20), forming desmosomal contacts with the superficial ones. These cells possessed extensive, narrow processes which, in Figure 17, can be seen wrapping round small, superficial axons. At this stage the larger axons in some preparations appear collapsed (Fig. 17).

Figure 17. Cells with extensive interdigitating processes, atypical cytoplasmic features and large extracellular spaces lying beneath the neural lamella. Magnification $\times 7,870$. The inset is of opaque granules seen within these cells. Magnification $\times 15,740$. The large arrowhead points to an atypical subperineurial cell with processes wrapping round the axons. An apparently collapsed axon is also shown $\left(a_{1}\right)$. Cells are shown 4 days after treatment and incubation in lanthanum chloride.

Figures 18 and 19. A septate and possible tight junction (arrowheads) between the interdigitating cells seen in Figure 17. Magnification: Figure 18, × 79,680; Figure 19, × 30,520.

Figure 20. Desmosomal contact between the subperineurial cell shown in Figure 17 and the interdigitating cells. Magnification $\times 30,520$.

Figure 21. Another preparation, 4 days after treatment, in which the cell processes beneath the neural lamella are closer together and the extracellular space is greatly reduced. Magnification $\times 7,870$.

Figure 22. A granule-containing cell between the axons, 4 days after treatment with ethidium bromide. Magnification $\times 7,870$. 
Lanthanum penetration. Four days after ethidium treatment extraneously applied lanthanum no longer penetrated beyond the inner margin of the superficial layer of cells (Fig. 17).

Electrophysiology. At this stage there was considerable variation in the electrical responses of the axons to externally applied, high-potassium saline, indicating variable degrees of intercellular access of potassium ions to the axon surfaces (Fig. 23). In contrast, saline-treated, control connectives showed no equivalent reduction in spike amplitude during exposure to high-potassium saline, implying that restoration of the bloodbrain barrier had occurred (Fig. 24).

\section{Effects after 6 days}

Ultrastructure. The superficial cells were now in tightly opposed layers, similar to those shown in Figure 21. Deeper within the connectives, healthy glial nuclei were present and the mesoaxonal processes were now closely spiraled, as in normal preparations (Fig. 25). Occasionally seen were relatively large areas of closely packed cell processes, resembling those of neuroglia (Fig. 26). The axons appeared to be completely nor$\mathrm{mal}$ at this stage. There were no infoldings of the axon membranes and mitochondrial densities were as seen in control preparations.

Electrophysiology. There was less variation between individual preparations in respect to high-potassium pulses. The decline in the amplitudes of the action potentials occurred less rapidly than earlier: the fastest response corresponding to the slowest one measured at 4 days (Fig. 27).

\section{Changes at 9 to 28 days after treatment}

Ultrastructure. Eleven days after ethidium treatment the cells beneath the neural lamella had acquired the morphological characteristics of those in the normal perineurium. They were flattened, with processes extending downward into the underlying tissues (Fig. 29). Septate and gap junctions were present between adjacent cell membranes. The cell contents had darkened in appearance. Rarely, subperineurial cells with electron-dense granules were seen with large cytoplasmic inclusions containing membrane debris (Fig. 28). After 28 days the superficial cell layer of the connectives was indistinguishable from the perineurium of unoperated nerve cords.

The deeper tissues of the connectives hac also reorganized by this time, the only significant abnormal feature being the very infrequent occurrence of granule-containing cells (11 days after ethidium treatment; Fig. 30). These shared many of the cytoplasmic features of the granule-containing cells observed 1 day after treatment (see Fig. 10). It is possible, in fact, to recognize a sequence of involvement of granule-containing cells during ethidium-induced damage and repair. After their initial appearance and increase up to 4 days, their numbers gradually reduced until at 1 month no cells with cytoplasmic granules were seen. In an extreme case ( 4 days after ethidium treatment), cells containing granules appeared stacked outside the former margin of the connective, adhering the nerve cord to the cuticle in the region of operation. As can be seen in Figure 32, there was no clear boundary between these granule ceils and the underlying tissues. Where neural lamella was present granulecontaining cells were seen penetrating it (Fig. 31). In other preparations (Fig. 33), similar cells formed a perineurium-like layer beneath the neural lamella. These cells, particularly those

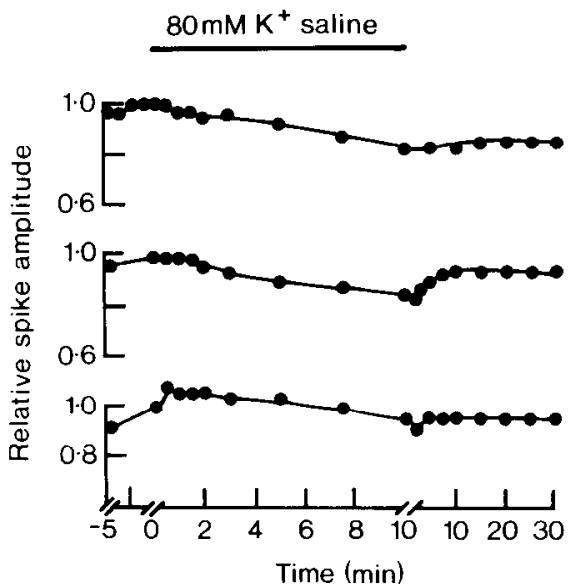

Figure 24. Four days after the control cords were treated with saline, only there is no reduction in spike amplitude (sucrose gap recordings) equivalent to that seen in Figure 23. This implies the restoration of the blood-brain barrier.

stacked on the outside of the cord, share a number of features with hemocytes including the presence of cytoplasmic granules and cell processes.

Electrophysiology. After 11 days there was no appreciable effect of raised external potassium on spike amplitude, suggesting that the blood-brain barrier had been re-established (Fig. 35). There was thus a progressive decrease in intercellular permeability of the blood-brain interface to this cation between 6 and 11 days. $\Lambda$ t 9 days an intermediate condition was observed in which there was a relatively slow effect of high-potassium saline on axonal action potentials (Fig. 34).

The above electrophysiological results indicate that by 11 days restriction to intercellular penetration had been re-established. This, together with the restricted access of lanthanum (after 4 to 6 days), implies that the perineurial blood-brain barrier had been restored. However, the overall permeability properties of the repaired blood-brain interface differed from those of normal, control cords. This is indicated by the potential changes during exposure to high $[\mathrm{K}]$ saline measured in ethidium-treated preparations after 11 days (Fig. 36c). In control cords, taken directly from unoperated animals, relatively rapid DC potential changes were recorded on exposure to highpotassium and return to normal saline (Fig. 36a). In contrast, the slower DC potential changes measured after 1 day largely resulted from axonal depolarization, which caused the observed conduction block in high-potassium saline (Fig. 36b). After 11 days the DC potential changes again appear to be of extraneuronal origin, for there was no measurable effect on the amplitude of the action potential during exposure to high potassium (Fig. 36c). However, these extraneuronal potential changes were smaller (resting potential falling to $-47 \pm 2.5 \mathrm{mV}$ after 1 min in high $\mathrm{K}^{\prime}$ saline). This suggests that the original permeability properties of the repaired blood-brain interface had not yet been fully restored by 11 days. By 28 days, however, the shift of extraneuronal potential induced by potassium was similar to those recorded in normal cords from unoperated animals (resting potential falling to $-34 \pm 3 \mathrm{mV}$ after $1 \mathrm{~min}$ in

Figure 25. a, A normal glial cell between the axons 6 days after ethidium bromide treatment. Magnification $\times 7,110 . b$, Densely packed mesoaxonal glial processes. Magnification $\times 11,930$. c, A desmosomal contact between processes of the mesoaxonal glia. Magnification $\times 35,000$.

Figure 26. An abnormally large area of closely packed cell processes, resembling neuroglia, between the axons of the cord 6 days posttreatment. Magnification $\times 7,110$.

Figure 28. A granule cell, with a large cytoplasmic inclusion of membrane debris beneath the perineurium, 11 days post-treatment. Magnification $\times 7,110$.

Figure 29. Eleven days after ethidium bromide treatment, cells beneath the neural lamella have acquired some of the characteristics typical of normal perineurium. A cell process extends into the subperineurial tissue (arrowhead). Magnification $\times 11,930$. 

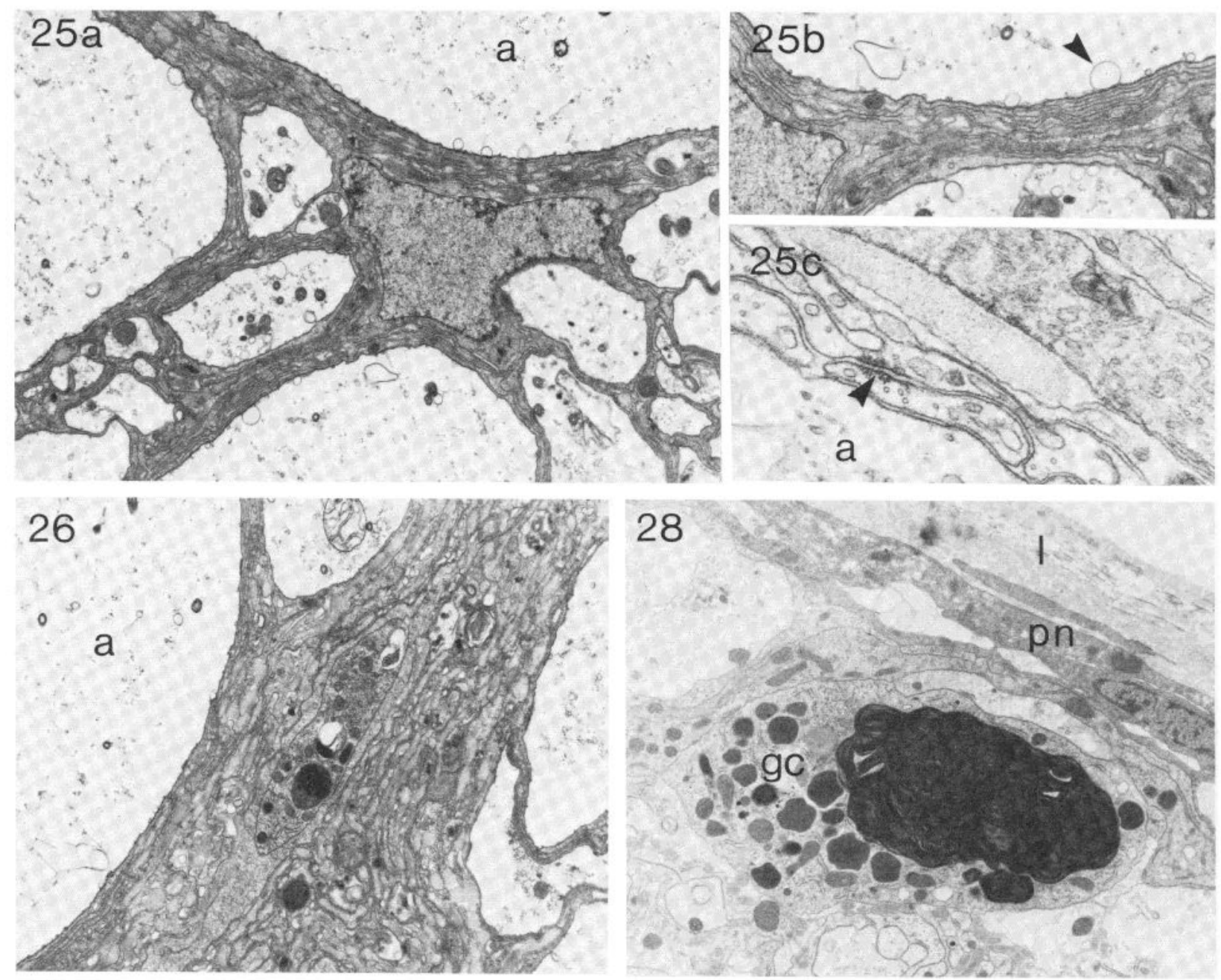

29
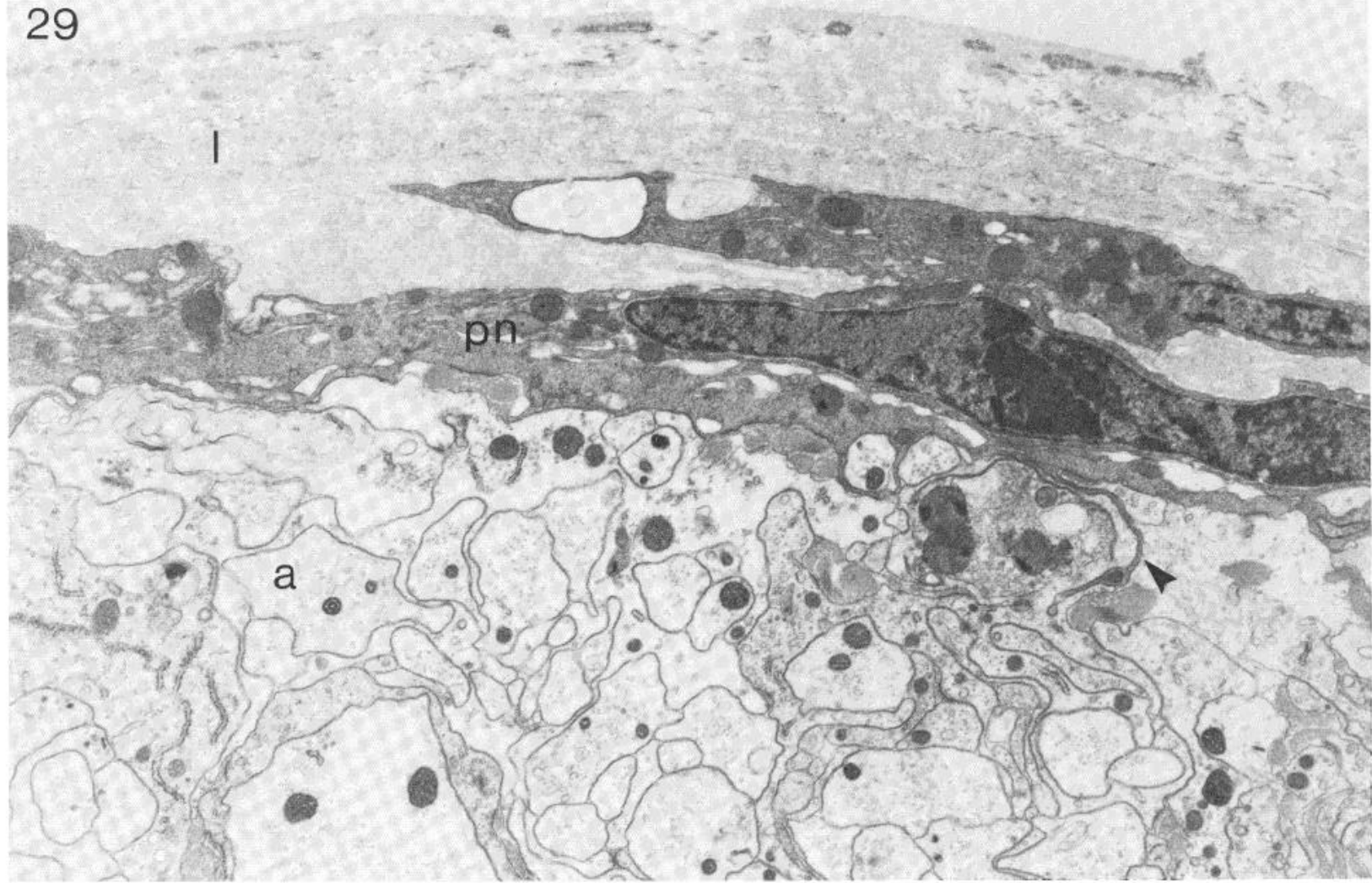

Figures 25, 26, 28, and 29 


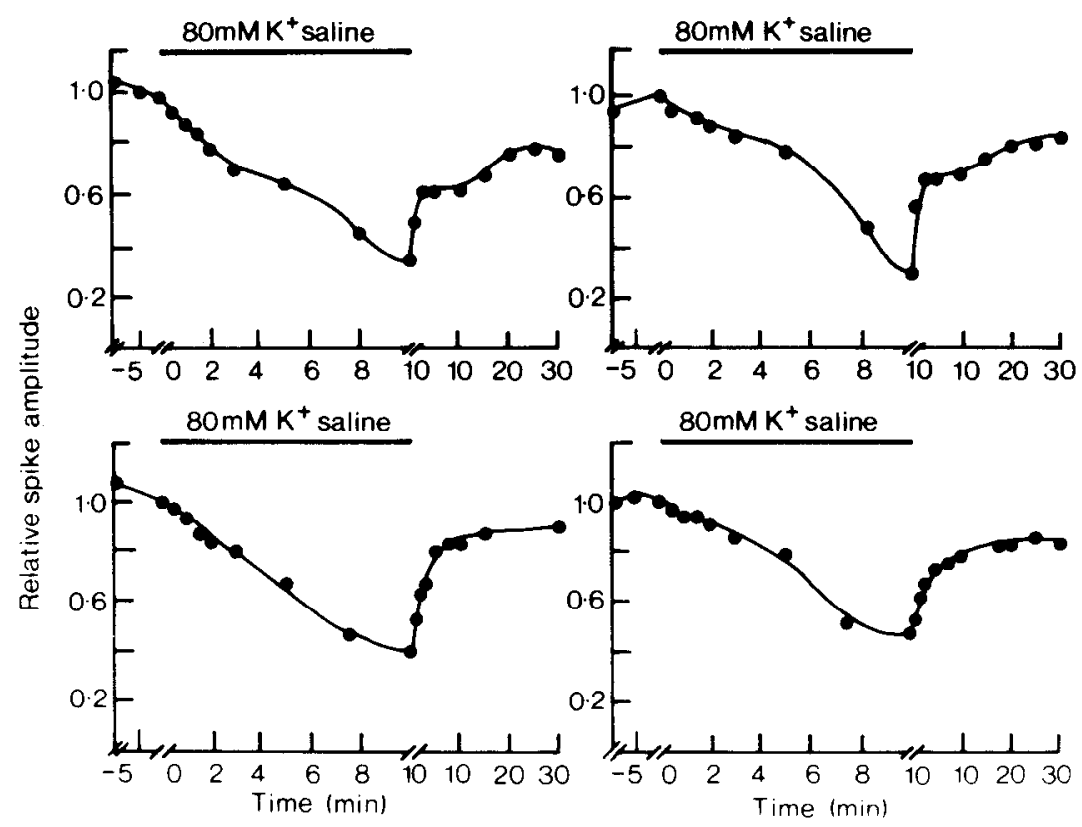

Figure 27. Six days after treatment with ethidium bromide, the intercellular permeability of the cords to potassium is less variable than at 4 days and on average is reduced (sucrose gap recordings).

high $\mathrm{K}^{+}$saline), suggesting a slower restoration of the passive ionic permeability of the blood-brain interface (Fig. 36d).

\section{Discussion}

Our observations show that ethidium bromide selectively disrupts the glial elements in cockroach central nervous connectives. This was seen most clearly in the perineurial glia which showed drastic structural changes within $24 \mathrm{hr}$. Deterioration was also seen in the subperineurial and, particularly, the mesaxonal glia.

Despite the extensive glial damage induced by ethidium bromide, conduction of action potentials persisted throughout the period of damage and repair. However, some ultrastructural changes occurred in the axons. Thus, although the axoplasm was not noticeably disrupted, increased numbers of mitochondria were seen and axon membranes were frequently wrinkled or invaginated. In extreme cases, the giant axons tended to collapse between 2 and 4 days. Mitochondrial increase and the membrane convolutions are also characteristic of mechanically damaged axons (Meiri et al., 1983). It is conceivable, therefore, that the axonal responses induced by mechanical damage may result not only from direct effects on the axons but also from indirect changes caused by glial disruption. The increase in mitochondrial numbers in transected cockroach axons has been suggested to be a local response caused by changes in "ionic composition" or "secondary biochemical changes" at the site of the lesion (Meiri et al., 1983) - effects which, in part at least, might be predicted to result from glial damage.

Repair was clearly in progess after 4 days. However, although the cells seen at both the periphery and at deep levels of the connectives appeared healthy at this stage, their morphology was variable and very different from that of normal neuroglia. The structural variation of these peripheral cells was paralleled by the electrophysiological responses in experimental connectives at this time, which indicated variable degrees of intercel- lular access of potassium ions to the axon surfaces. The progressive restoration of a functional blood-brain barrier between 4 and 11 days was associated with a gradual re-establishment of an apparently normal perineurial ultrastructure.

The restored blood-brain barrier at 11 days showed smaller extraneuronal potential changes on exposure to high-potassium saline than were measured in normal, untreated cords. This suggests that the ion selectivity of the blood-brain interface, in repairing connectives, differed from that of the normal perineurium and was only gradually re-established after 28 days.

Our observations show that selective damage to the neuroglia produce effects very different from those obtained by cutting connectives. $A \mathrm{~s}$ shown in the preceding paper (Treherne et al., 1984), such mechanical disruption (which involves damage to glia, neurons, and extracellular elements) produces very dramatic changes, notably, extensive proliferation of glial processes and dramatic extracellular changes, including massive secretion of intercellular matrix. In addition, there was no production of a blood-brain barrier, and ionic lanthanum was able to penetrate deeply into the tissues 28 days after nerve section. 'This repair contrasts with the controlled restructuring obtained following selective glial disruption and suggests that the presence of undamaged neurons, and/or the extracellular matrix framework, is able to direct re-forming cellular elements.

A consistent feature of glial damage and repair was the prominent involvement of granule-containing cells, never seen in control cords. They appear throughout the tissues of ethidium-treated connectives within $24 \mathrm{hr}$ and the numbers increase for up to 4 days. From 24 to $48 \mathrm{hr}$, granule-containing cells appeared on the outer surface of the neural lamella and also penetrated into the disrupted perineurium. Cells containing very similar granule inclusions were seen behaving in a phagocytotic manner among the damaged perineurial cells. Later, cells with large inclusions of membrane debris occurred in the peripheral tissues. These could have been involved in the final

Figure 30. A granule cell among the glia adjacent to the axon 11 days after treatment with ethidium bromide. Magnification $\times 8,640$.

Figure 31. A hemocyte apparently penetrating the neural lamella, 4 days post-treatment. Magnification $\times 8,640$.

Figure 32. Hemocytes stacked outside the cord with no clear neural lamella or perineurium present. This preparation was examined 4 days after ethidium bromide treatment and had, atypically, become stuck to the ventral abdominal plates by the hemocytes. Magnification $\times 5,690$.

Figure 33. Granule cells forming a precise layer beneath the neural lamella, 2 days after treatment with ethidium bromide. Magnification $\times$ 5,690 . 

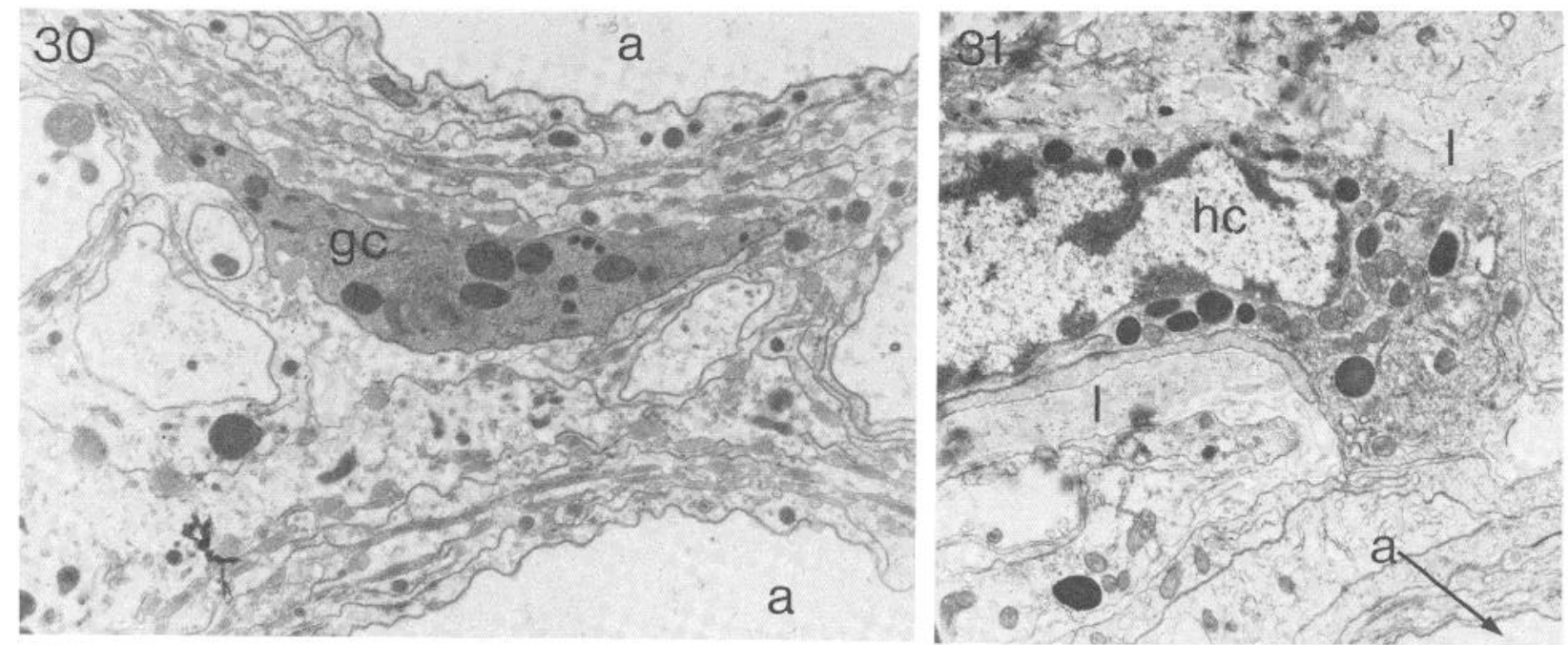

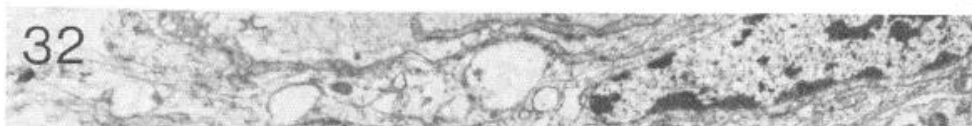

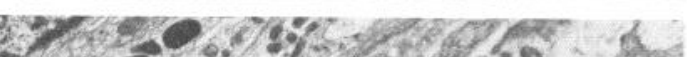

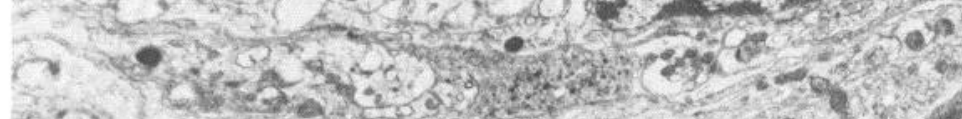

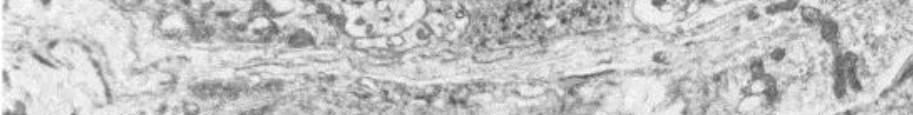
If

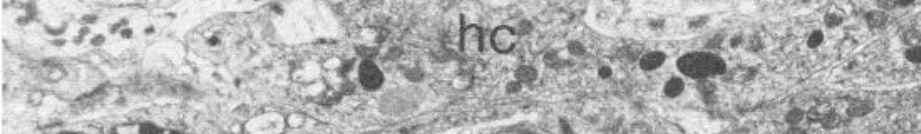

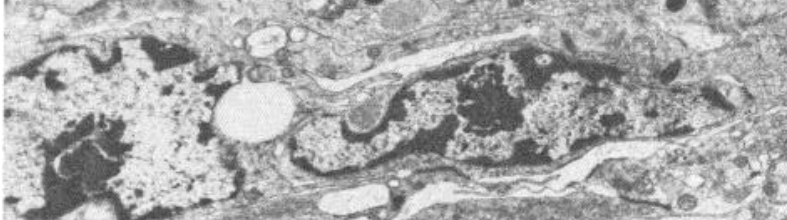

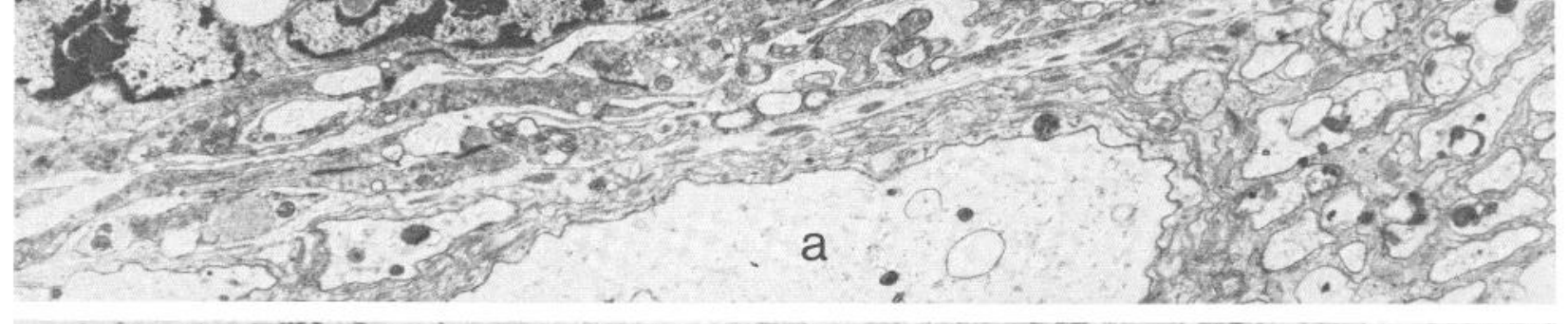

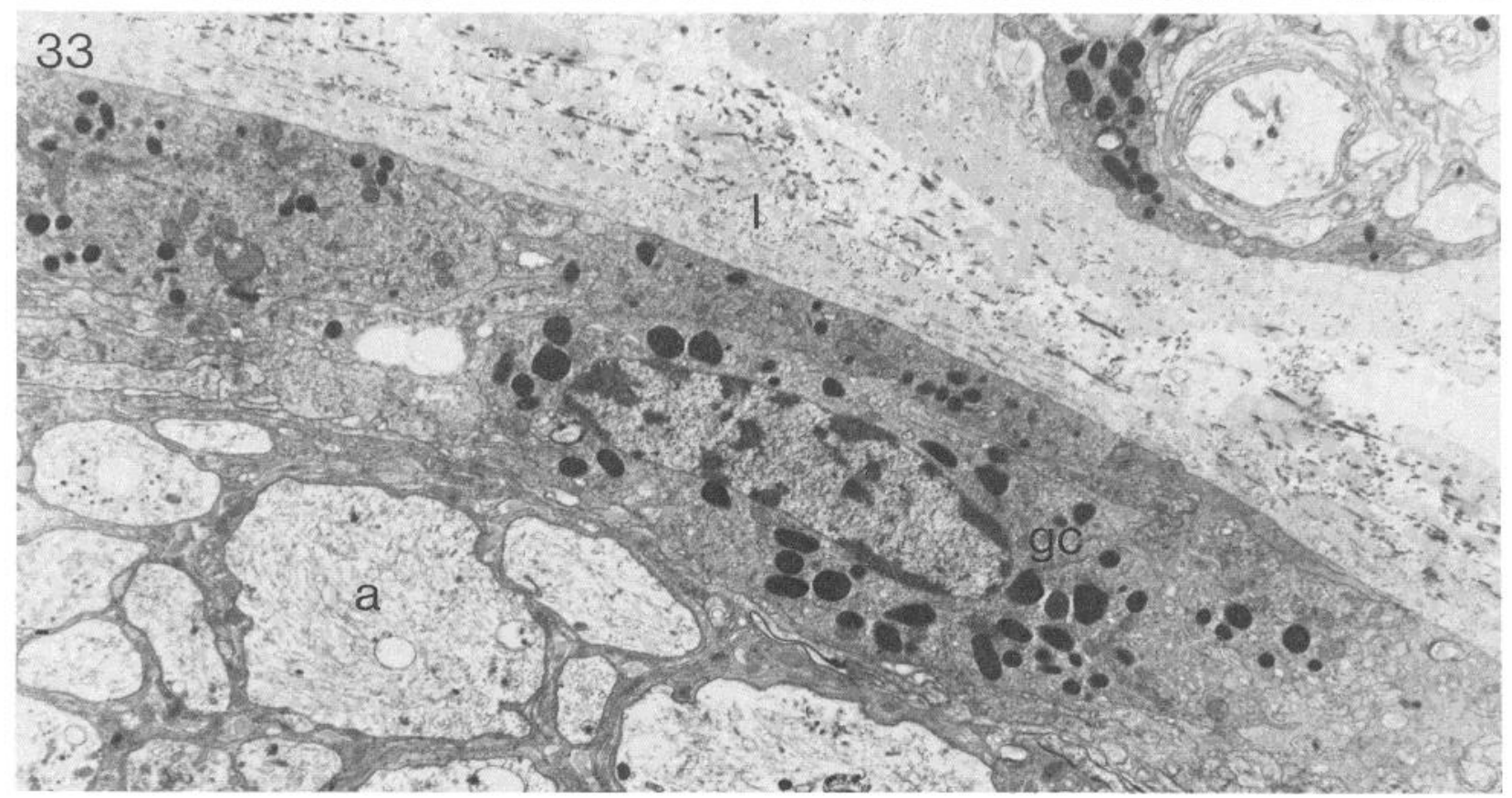




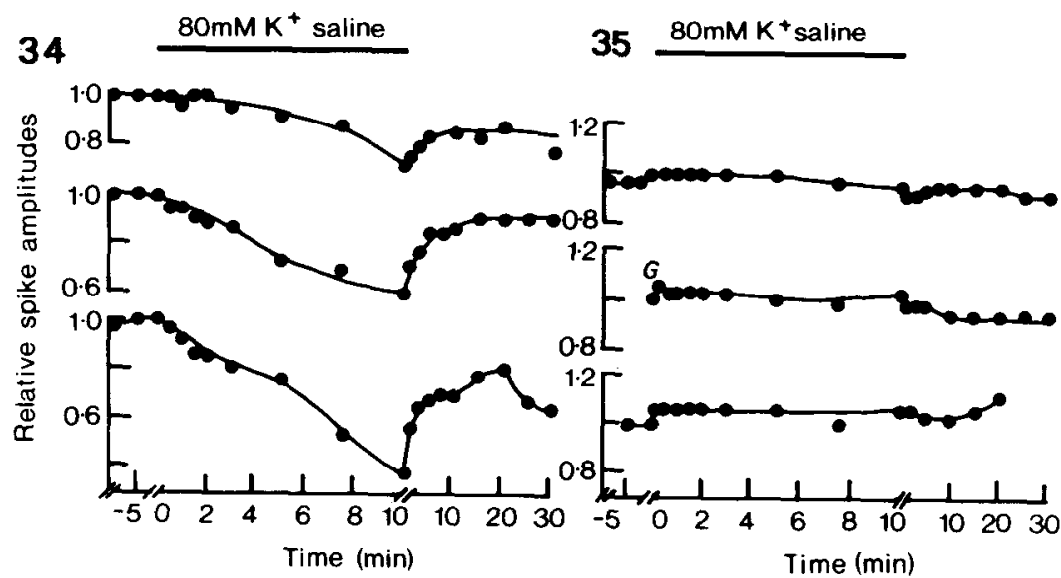

Figure 34. When compared with the relative spike amplitudes in Figures 23 and 27, the sucrose gap-recordcd spike 9 days after ethidium bromide treatment implies a gradual restoration of the blood-brain barrier. The application of high-potassium saline still produces a variable result, but the reduction in spike amplitude after 10 min is becoming progressively smaller.
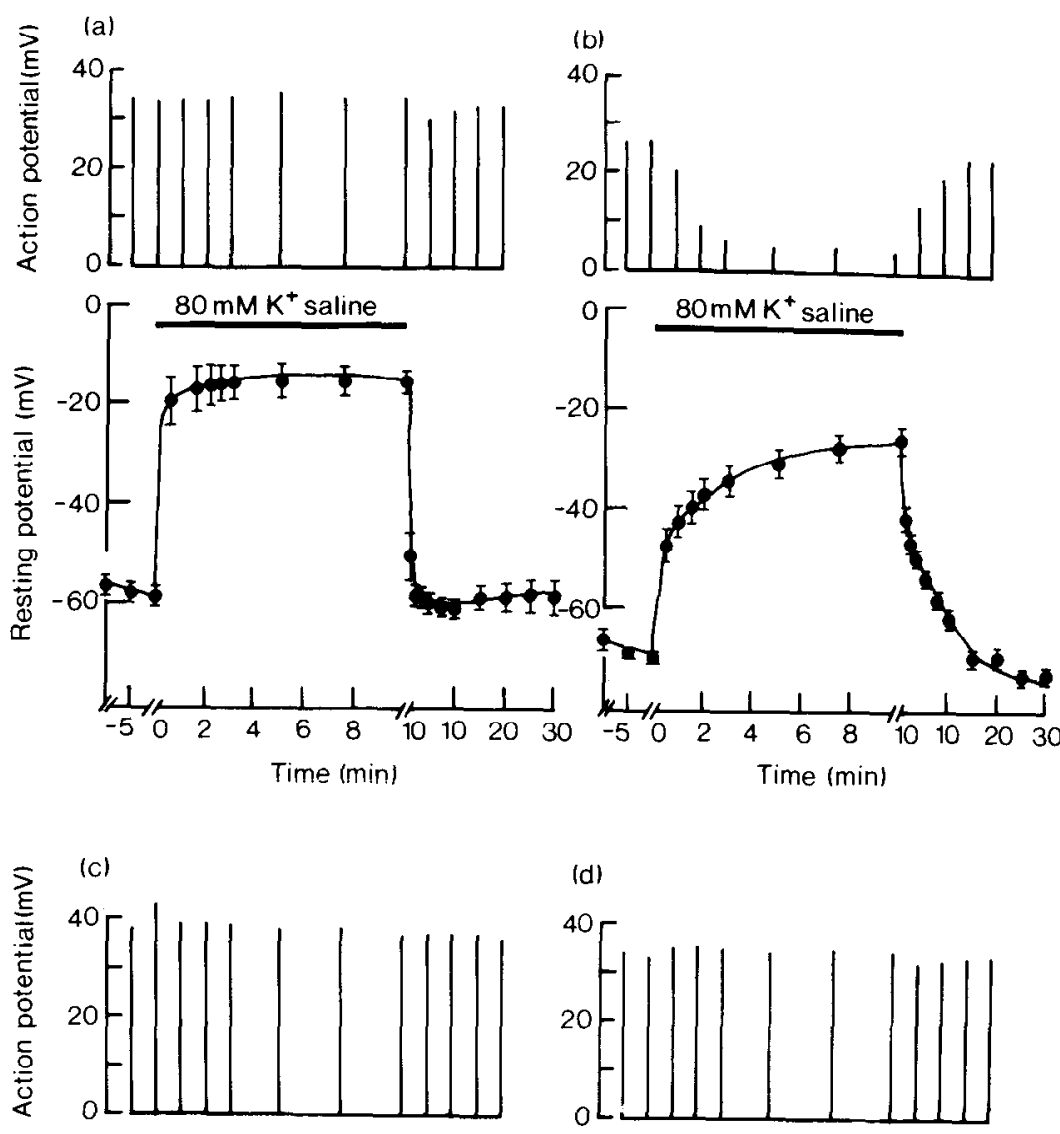

(d)
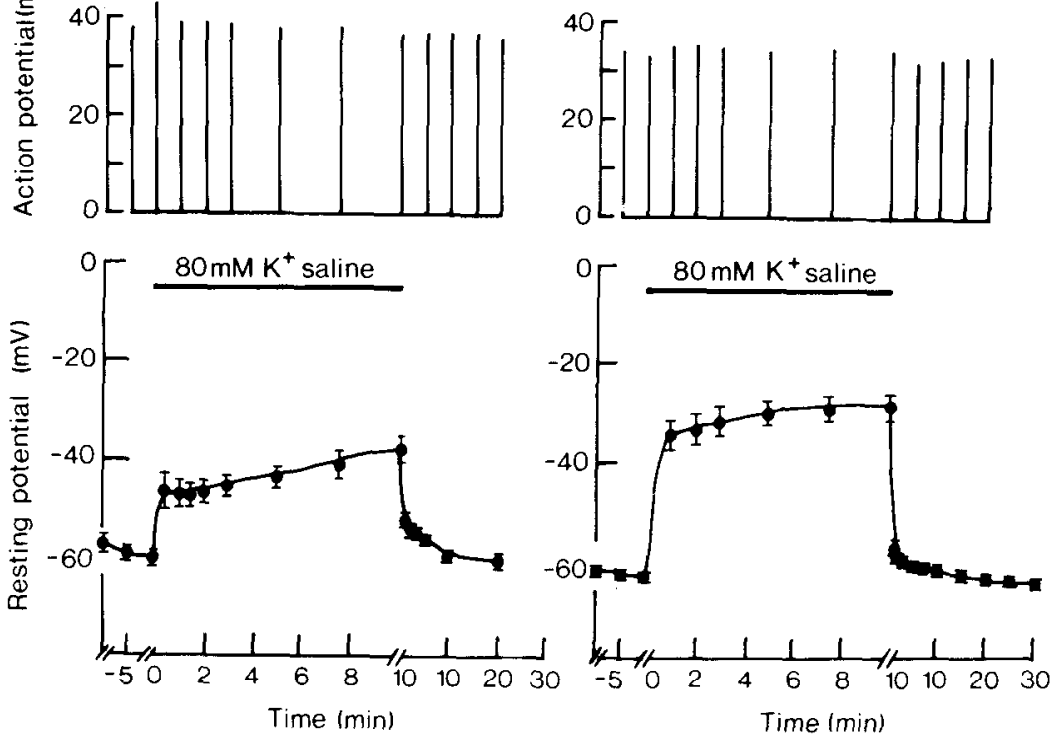

Figure 35. The restoration of a blood-brain barrier is clearly seen 11 days after ethidium bromide treatment. The high-potassium saline no longer reduces the amplitude of the action potentials (sucrose gap recordings). 
stages of phagocytosis. After $48 \mathrm{hr}$, granule-containing cells, or their processes, could also form layers at the periphery of the connectives. These showed no obvious signs of phagocytotic activity. Similar cells were also found deep within the connectives, among the mesaxonal glia.

At 4 to 6 days, the morphology of the cells at the surface had assumed characteristics similar to those of normal perineurium. However, the cytology of these repairing cells was very different from that of normal perineurial cells, notably by the continued presence of granular inclusions. From 6 to 11 days, the cytology of the peripheral cells changed progressively and by 28 days the cells in this locus were indistinguishable from those of the perineurium in normal, untreated animals. These progressive changes in structure paralleled the re-establishment of the normal permeability properties of the blood-brain interface outlined above.

Our observations suggest that the granule-containing cells play an integral role in the repair of the lesion. The origin of these cells is unknown. Two possibilities exist: they could be of glial origin, perhaps equivalent to the mobile microglia observed in the leech CNS (Morgese et al., 1983), or derived from hemocytes. The second possibility is certainly feasible, for these cells share a number of cytological features with hemocytes, which were seen, in the early stages, adhering to and penetrating the neural lamella. In vertebrates, blood monocytes invade damaged brain tissues and transform into macrophage cells which may secrete a glial growth factor (Fontana et al., 1980; Adrian and Schelper, 1981).

The situation in vertebrates, however, is complex-as emphasized by Gilmore and Walls (1981), the origin and identity of "reactive" cells have not been resolved. In the insect the granule cells, apparently equivalent to "reactive" cells, may serve dual functions: phagocytosis and a role in structural repair. However, we cannot predict whether these two functions are inherent in a single type of precursor cell or whether numerous cell types are involved, including the hemocytes. The circulating granulocytes (Gupta, 1979) share many cytoplasmic features with those cells stacked on the surface and penetrating the neural lamella in the early stages of response to ethidium bromide treatment. The possibility exists that all granule or "reactive" cells within the connectives are derived from circulating granulocytes. Alternatively, the phagocytic and repair functions could be mediated by two previously differentiated cells types.

The question now arises as to the fate of the nonphagocytic granule cells. There are two obvious possibilities. They could be progressively replaced by neuroglia during the latter stages of repair or they could persist and gradually undergo change to become functional neuroglia.

\section{References}

Adrian, E. K., and R. L. Schelper (1981) Microglia, monocytes and macrophages. In Glial and Neuronal Cell Biology, 11th International Congress of Anatomy, E. A. Vidro and S. Federoff, eds., Part A, pp.
113-124, Alan R. Liss, Inc., New York.

Blakemore, W. F. (1982) Ethidium bromide induced demyelination in the spinal cord of the cat. Neuropathol. Appl. Neurobiol. 8: 365-375.

Fontana, A., A. Grieder, S. Arrenbrecht, and P. Grob (1980) In vitro stimulation of glial cells by a lymphocyte-produced factor. J. Neurol. Sci. 45: 55-62.

Gilmore, S. A., and R. C. Walls (1981) Patterns of labeling of intraspinal reactive cells in rats injected with $\left[{ }^{3} \mathrm{H}\right]$ thymidine prior to or following sciatic axotomy. Brain Res. 218: 1-13.

Gupta, A. P. (1979) Hemocyte types: Their structures, synonymies, interrelationships and taxonomic significance. In Irsecl HemocylesDevelopment, Forms, Functions and Techniques, A. P. Gupta, ed., pp. 85-127, Cambridge University Press, Cambridge, England.

Holder, R. E. D., and D. B. Sattelle (1972) A multiway non-return valve for use in physiological experiments. J. Physiol. (Lond.) 226: $2-3 \mathrm{P}$.

Lane, N. J. (1981) Invertebrates neuroglia-junctional structure and development. J. Exp. Biol. 95: 7-33.

Lane, N. J., and J. E. Treherne (1972) Studies on perineurial junctional complexes and sites of uptake of microperoxidase and lanthanum in the cockroach central nervous system. Tissue Cell 4: 427-436.

Meiri, H., A. Dormann, and M. E. Spira (1983) Comparison of ultrastructural changes in proximal and distal segments of transected giant fibres in the cockroach Periplaneta americana. Brain Res. 263. $1-12$.

Morgese, V. J., E. J. Elliot, and K. J. Muller (1983) Microglial movement to sites of nerve lesion in the leech CNS. Brain Res. 272: 155170.

Pichon, Y., and J. E. Treherne (1970) Extraneuronal potentials and potassium depolarization in cockroach giant axons. J. Exp. Biol. 53. $485-493$.

Pichon, Y., R. B. Moreton, and J. E. Treherne (1971) A quantitative study of the ionic bases of extraneuronal potential changes in the central nervous system of the cockroach (Periplaneta americana L.). J. Exp. Biol. 54: 757-777.

Schofield, P. K., and J. E. Treherne (1984) Localization of the bloodbrain barrier of an insect: Electrical model and analyses. J. Exp. Biol. 109: 319-331.

Schofield, P. K., L. S. Swales, and J. E. Treherne (1984) Potentials associated with the blood-brain barrier of an insect: Recordings from identified neuroglia. J. Exp. Biol. 109: 307-318.

Treherne, J. E., and Y. Pichon (1972) The insect blood-brain barrier. Adv. Insect Physiol. 9: 257-313.

Treherne, J. E., and P. K. Schofield (1981) Mechanisms of ionic homeostasis in the central nervous system of an insect. J. Exp. Biol. 95: 61-73.

Treherne, J. E., P. K. Schofield, and N. J. Lane (1973) Experimental disruption of the blood-brain barrier system of an insect (Periplaneta americana). J. Exp. Biol. 59: 711-723.

Treherne, J. F., J. B. Harrison, I. M. Treherne, and N. J. Lane (1984) Glial repair in an insect central nervous system: Effects of surgical lesioning. J. Neurosci. 4: 0000-0000.

Waring, M. J. (1981) DNA modification and cancer. Annu. Rev. Biochem. 50: 159-192.

Yajima, K., and K. Suzuki (1979a) Ultrastructural changes of oligodendroglia and myelin sheaths induced by ethidium bromide. Neuropathol. Appl. Neurobiol. 5: 49-62.

Yajima, K., and K. Suzuki (1979b) Demyelination and remyelination in the rat central nervous system following ethidium bromide injection. Lab. Invest. 41: 385-392.

Figure 36. Examples of the resting potential, with a diagrammatic representation of the concomitant action potential (sucrose gap recordings) from preparations at different stages of treatment. Standard errors are shown on both sides of the mean. $a$, Untreated cords showing the persistence of the action potential during application of the high-potassium saline and resting potential change caused by the depolarization of the outwardly directed perineurial membranes $(n=3) . b$, Changes in the resting potential 1 day after ethidium bromide treatment are caused largely by axonal depolarization, resulting in a conduction block $(n=4)$. $c$, Eleven days from ethidium bromide treatment, the DC potential changes appear to be largely extraneuronal in origin as the increased potassium concentration no longer affects the action potential. However, the resting potential reduced $(n=3) . d$, Twenty-eight days after treatment the resting potential changes are similar to those of control cords $(n$ $=4)$. 